ance to call in the family doctor to see a sick infant, particularly late at night, at the week-end, or on his day off. No fewer than $80 \%$ of the families concerned had serious problems, such as marital disharmony, inadequate or erratic income, poor housing, not solely overcrowding, or chronic physical or mental illness. This prevalence was significantly greater than in a control group. Another finding, the importance of which is as yet obscure, was that in $55 \%$ of the families the mother was unable to communicate with the father during the night when the child died.

You do not suggest what incipient symptoms (and signs ?) should be looked for, presumably in the first place by parents. In my series the mothers of about a quarter of the infants had noted the signs mentioned in the Liverpool study-lack of response, stupor, pallor, and cyanosis-together with failure to feed, for a day or two before death without obtaining medical attention. This was not the result of indifference or lack of intelligence. It is to be hoped that future studies of large groups of infants of this kind will include an examination of the social circumstances in which the death took place, covering not so much such items as the bedding, feeding, and housing dealt with in a recent study, ${ }^{2}$ as the attitudes and general patterns of behaviour of the family as a group. It may be that preventive action based on such knowledge would do more to reduce the number of deaths from this condition than the present possibilities of specific therapy.-I am, etc.,

\section{H. Vaughan.}

\section{Department of Social and \\ University of Manchester, Manchester. \\ REFERENCES}

19 roy. Coll. gen. Practit., 1968, 16, in press. Ministry of Health Enquiry Into Sudden Death in Infancy. Reports on Public Health and
Medical Subjects, 1965, No. 113 . H.M.S.O. London.

\section{Screening for Phenylketonuria}

SIR,-With reference to the publication of the report of the Medical Research Council's working party on phenylketonuria (5 October, p. 7) we feel that further attention should be drawn to the merits of a partition chromatography test based on that described by Scriver $^{1}$ presently in use in Kingston upon Hull.

As a result of waning confidence in the Phenistix test, a screening test for phenylketonuria utilizing a drop of blood was commenced in Kingston upon Hull in February $1967,{ }^{2}$ and has now replaced almost all other screening procedures. ${ }^{3}$ The test is initiated by both hospital and domiciliary midwives at the end of the baby's first week of life. The blood is obtained by heel prick, collected in heparinized capillary tubes, and is sent to the city analyst, who undertakes the chromatography. A second test is performed when the babies reach 6 or 8 weeks of age, the blood being collected on this occasion by health visitors and again being forwarded to the city analyst for chromatography. No instances of sepsis have been reported following the heel prick.

By this means, in the past 20 months 7,261 infants have been examined, a total of 13,233 tests having been performed. This represents an acceptance rate of $97 \%$ by the parents in respect of whose children the test has been offered, the small remaining number still being tested by Phenistix.

The Scriver style test has several features to commend it. It is extremely easy to perform. It is easy to interpret. It has received good parent acceptance, and it enables several other aminoacidopathies to be tested for simultaneously. So far in Kingston upon Hull it has detected two cases of phenylketonuria and 42 episodes of transient elevation of aminoacids concerning mainly phenylalanine, tyrosine, and methionine.-We are, etc.,

\section{J. M. O'BRIEN,}

Deputy Medical Officer of Health. M. G. Philpott,

Health Department Consultant Paediatrician.

Kingston-upon-Hull, Yorks.

\section{REFBRENCES} Mellon, J. P., and Stiven, A. G., F. med. Lab.

3 Hutchison, A., Med. Offr, 1967, 118. 64

utchison, A., and O'Brien, J.' M., Med. Offr, 1968, 119, 189 .

\section{Gastric Ulcers in Nigeria}

SIR,-Dr. A. M. Gill's current practice article on gastric ulcer (17 August, p. 415) makes no mention of epidemiology or the

\section{Treatment of Angina Pectoris}

SIR,-The study of Dr. G. Sandler and others (27 July, p. 224) was scrupulous in the determination of both objective and subjective responses to the drugs being investigated. Their summary leaves the impression that verapamil and propranolol are of therapeutic value in the treatment of angina pectoris. Such conclusions should not be drawn from the data presented.

The decreased trinitrin consumption in their study from 17.4 tablets per week during control (no drug) period to 11.2 during placebo is considerable, though not statistically significant at the $5 \%$ level. The authors appear to have summarily discounted this response to placebo, apparently because it failed in their significance test. They then continued to make comparisons of treatment

periods with the control period and not with the placebo period.

The particular method by which the statistical analysis was performed is not described, nor is it clear from the tables appearing in the article. One of us has made statistical comparisons from the data available on the number of recorded attacks and trinitrin used during the various periods of observation. Single tail t-tests were done in comparing placebo and drug treatment periods with control and again comparing the active drugs with placebo (see Tables). We find significant changes similar to those noted by the authors when comparison is made between the control period and treatment periods. There was no significant $(P>0.05)$ reduction in anginal attacks or trinitrin used during the

TABLE I.-Comparison with Control

\begin{tabular}{|c|c|c|c|c|c|}
\hline & Control & Placebo & $\begin{array}{l}\text { Propranolol } \\
\text { (100 mg. tds.) }\end{array}$ & $\begin{array}{l}\text { Verapamil } \\
\text { (40 mg. tds.) }\end{array}$ & $\begin{array}{l}\text { Verapamil } \\
\text { (120 mg. tds.) }\end{array}$ \\
\hline $\begin{array}{c}\text { Recorded attacks: } \\
\text { Mean } \pm \text { S.E.* } \\
\text { P } \quad \text {.. }\end{array}$ & $9 \cdot 7 \pm 2 \cdot 4$ & $\begin{array}{c}6.5 \pm 1.9 \\
0.15<\bar{P}<0.20\end{array}$ & $\begin{array}{c}4.3 \pm 1.8 \\
0.025<\frac{\mathrm{P}}{<0.05}\end{array}$ & $\begin{array}{c}4.4 \pm 1.0 \\
0.025<\frac{\mathbf{P}}{<}<0.05\end{array}$ & $\begin{array}{c}4.0 \pm 1.0 \\
0.0125<\mathbf{P}<0.025\end{array}$ \\
\hline $\begin{array}{c}\text { Trinitrin used: } \\
\text { Mean } \pm \text { S.E. } \\
\mathbf{P} \quad \ldots\end{array}$ & $17 \cdot 4 \pm 3 \cdot 1$ & $\begin{array}{c}11.2 \pm 3.0 \\
0.05<\bar{P}<0.10\end{array}$ & $\begin{array}{c}9.0 \pm 2.9 \\
0.025<\frac{\mathrm{P}}{\mathrm{P}}<0.05\end{array}$ & $\begin{array}{c}11.0 \pm 2.8 \\
0.05<\mathrm{P}<0.10\end{array}$ & $\begin{array}{c}6.9+2.2 \\
0.0025<\bar{P}<0.005\end{array}$ \\
\hline
\end{tabular}

TABLE II.-Comparison with Placebo

\begin{tabular}{|c|c|c|c|c|c|}
\hline & Control & Placebo & $\begin{array}{l}\text { Propranolol } \\
\text { (100 mg. tds.) }\end{array}$ & $\begin{array}{l}\text { Verapamil } \\
\text { (40 mg. tds.) }\end{array}$ & $\begin{array}{c}\text { Verapamil } \\
\text { (120 mg. tds). }\end{array}$ \\
\hline $\begin{array}{l}\text { Recorded attacks: } \\
\text { Mean } \pm \text { S.E. } \\
\text { P }\end{array}$ & & $6.5 \pm 1.9$ & $\begin{array}{c}4.3 \pm 1.8 \\
0.20<\mathrm{P}<0.25\end{array}$ & $\begin{array}{c}4.4 \pm+1.0 \\
0.15<\frac{\mathrm{P}}{2}<0.20\end{array}$ & $\begin{array}{c}4.0 \pm 1.0 \\
0.10<P<0.15\end{array}$ \\
\hline $\begin{array}{l}\text { Trinitrin used: } \\
\text { Mean } \pm \text { S.E. } \\
\mathbf{P} \quad \ldots\end{array}$ & & $11 \cdot 2 \pm 3 \cdot 0$ & $\begin{array}{c}9.0 \pm 2.9 \\
0.30<P<0.35\end{array}$ & $\begin{array}{c}11.0 \pm 2.8 \\
0.475<\mathrm{P}<0.4875\end{array}$ & $\begin{array}{c}6.9 \pm 2.2 \\
0.10<P<0.15\end{array}$ \\
\hline
\end{tabular}

- S.E. $=$ Standard error of the mean. 
placebo period, whereas both are reduced significantly during propranolol and high dose verapamil treatment. During low dose verapamil treatment anginal attacks were reduced but trinitrin consumption was not. This suggests that placebo has no favourable effect on angina but propranolol and verapamil do. We have made further comparisons between the responses to the active drugs and the response to placebo which show no significant difference between the active drugs and the placebo. The conclusion then would be reached that propranolol and verapamil are no more effective than placebo in reducing either anginal attacks or trinitrin consumption. Our statistical analysis was made from the published data. Had the original data been available and analysis made using either paired t-tests or analysis of variance followed by Duncan's multiple range test our statistical results might have been somewhat different. We were puzzled by the mean change values given in the Tables since these are not simply the difference between the means.

Approximately $40 \%$ of patients included in such a study as this will improve on placebo. A control feature is essential to the design of such an anti-anginal study in which subjective responses are measured." The control feature designed into this study is the placebo period, and it, rather than the pretreatment period, must be used in data analysis to determine the therapeutic value of a pharmacologically active drug.-We are, etc.,

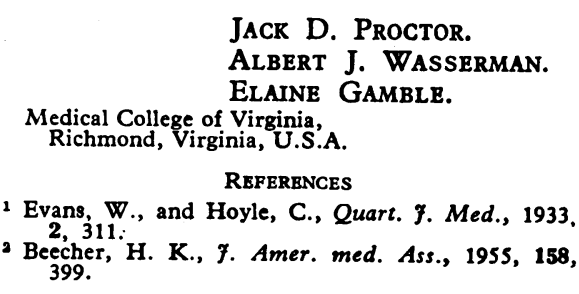

** We have shown this letter to Dr. G. Sandler and his colleagues, and they write:

"The letter from Drs. Proctor, Wasserman and Gamble is of interest in indicating an alternative method by which the data in our trial could be handled-namely, by comparing the results in the treatment periods with those during the placebo period instead of the control period. We are fully aware of the placebo effect in this type of trial with respect to the subjective data such as the incidence of angina recorded by the patient and his trinitrin consumption, and one of us has in fact repeatedly pointed this out in previous publications. ${ }^{1-4}$ If the mean trinitrin consumption (which is better subjective index than the recorded number of anginal attacks) with verapamil is compared with that in the placebo period we would accept that the mean values do not differ significantly. A more accurate comparison could be made by statistical analysis of the changes in trinitrin consumption in individual patients using verapamil compared with that particular patient's trinitrin consumption when having the placebo, and then the individual changes in the 16 patients (whether plus or minus) are analysed in the usual manner to give the mean difference (plus or minus), the variance, standard deviation, and standard error of the differences, and from these data it can be determined whether the mean difference is significantly different from zero. This valuable method of analysis, which appears to be unfamiliar to Drs. Proctor, Wasserman, and Gamble, is very well described in Facts from Figures by M. J. Moroney, 1962.
We have applied this more sensitive analytical method to the trinitrin results comparing verapamil $120 \mathrm{mg}$. t.d.s. with the placebo. Lack of space precludes us from detailing all the individual results, as it has also done in our paper, but with this method the mean change in weekly trinitrin consumption with verapamil was -4.53 , the variance was 73.22 , the standard deviation (including Bessel's correction for small populations) was 8.81 , the standard error 2.2 , value 2.1 , and $P$ is less than 0.05 , confirming that verapamil $120 \mathrm{mg}$. t.d.s. still leads to a significant reduction in trinitrin consumption when compared with the placebo.

However, these changes in the subjective parameters are of very limited value in assessing a new anti-anginal agent, and for a number of reasons, described by one of us in previous publications ${ }^{1-4}$ objective indices, provided by exercise tolerance tests, are of much greater value and importance. It will be seen in Table III that treatment with verapamil $120 \mathrm{mg}$. t.d.s. resulted in a significant reduction in S-T depression in the radiocardiogram occurring during exercise, and propranolol did the same; in addition, both verapamil $120 \mathrm{mg}$. t.d.s. and propranolol produced a significant reduction in the duration of S-T depression in lead VS after exercise, whereas placebo treatment, as expected, had no effect on either of these objective indices of ischaemia. Here it must be pointed out that these favourable results refer again to the more sensitive 'mean change' values as described above and not to the 'means.' The exercise electrocardiograms thus demonstrated clearly and objectively the beneficial effects of both verapamil $120 \mathrm{mg}$. t.d.s. and propranolol 100 mg. t.d.s. on the myocardial ischaemia occurring during exercise in anginal patients."-ED., B.M.J.

\section{REFERENCES}

1 Sandler, G., Brit. med. F., 1968, 3, 56 Sandler, G., Ilahi, M. A., and Lawson, C. W., Angiology, 1963, 14, 319

- Sandler, G., Brit. med. f., 1961, 2, 1741.

\section{Hess Test and Gout}

SIR,-Some months ago while rechecking a difficult blood pressure reading of a patient with acute gout, I noticed numerous purpuric spots developing on his forearm. A standard Hess test confirmed this, and when the attack of gout had responded to treatment the test became negative.

Since then I have seen several cases of acute arthritis, and only in those where the diagnosis proved to be primary gout was the Hess test positive. In none of these cases was the patient on any drug before the onset of the attack of gout, and there was no other cause for purpura present.

The reason for the increased capillary fragility is not clear, but I have found the Hess test a useful aid in the early diagnosis of atypical cases of gout.-I am, etc.,

\section{Virginia Water}

\section{J. Murray Bruce.}

\section{Hypnosis for Asthma}

SIR,-Your leading article (12 October, p. 67) is encouraging to those of us who have been studying physiological changes which follow suggestion under hypnosis. Hypnosis is an altered form of consciousness like attention, conscious reverie, delta sleep, and dream sleep. ' It has much in common with the last named, but, while in dream sleep the dreamer generally cannot react to his environment because of hypotonia of muscles and subsequent amnesia for the dream, under hypnosis the subject can mistake for reality the images produced in his mind by the operator.

The functions of the autonomic nervous system can be altered in three principal ways: by drugs, by reconditioning, and by hypnotic suggestion. We produced in volunteers an artificial but harmless neurosis by pairing a high tone with a painful stimulus to the finger, while a low tone was never so paired. We thus had a subject who would show a fear reaction with positive galvanic skin reflex (G.S.R.) and increased heart rate, while a low tone produced a slight slowing of the heart with a feeling of calm. ${ }^{2}$ In this way we could study neurosis objectively under laboratory conditions, including E.E.G. and respiration as well as heart rate and G.S.R. It has always been unsatisfactory that the psychiatrist is dependent for his understanding of neurosis almost solely on what the patient tells the physician of his subjective symptoms. The following have been some findings by means of this method.

The phenomena of hypnosis are genuine. If we try to condition the subject in the same way as before but make his hand anaesthetic to the painful shock before each session, then he does not become conditioned. If another subject is conditioned, and we make him deaf to the tone which has preceded the painful stimulus, then he does not show increase of heart rate or G.S.R. plus." In this second case, we were able to show by the averaged evoked potential that the block between the ear and the heart was in the region of the cochlear nucleus."

A common phenomenon in hypnosis is the psychomotor reaction ; for example, a suggestion is given that the subject's arm will raise itself upwards, and this movement is quite different from a voluntary movement. The important point is that this phenomenon affects not only voluntary muscles but involuntary muscles, for example, in the heart and bronchioles. A hypnotic suggestion can affect a specific part of the nervous system in as precise a manner as a drug like curare which affects the myoneural junctions. We devised experiments to test the relative strengths of hypnotic suggestion, conditioning, and drugs. Hypnosis is more powerful than the effects of conditioning, which it can either facilitate or inhibit. It thus alters the degree of effectiveness.

These studies emphasize the importance of the mental image, which is a phenomenon without which a physiologist cannot understand conditioning, but it is also the phenomenon on which the science of psychology and psychiatry are based. The study of conditioning and hypnosis in the laboratory is one of the most promising types of investigation at the present time and of great significance for the clinician. Such studies encourage the clinician to use this powerful instrument in asthma and other psychosomatic conditions. - I am, etc.,

London W.1

\section{A. Spencer Paterson.}

Psychiatrie Neurologie de, A. S., in Congress Psychiatrie Neurologie de langue francaise, 1964,
62 nd session, pp. 519-523. Marseille. Paterson, A. S., Bracchi, F., Passerini, A., Ppinelli, D., and Black, S.ìn Hypnosis and I sasner. Berlin. 3 Black, S., and Wigan, E. R., Brit. med. F., 1961.

- Spinelli, D., and Paterson, A. S., in Congres session, Nancy, 1963, pp. 326-332. Paris. 